\title{
Maintaining Stakeholder Trust in Difficult Times: Some Fundamental Reflections in Light of the Credit Crisis
}

\author{
Kai-Uwe Schanz \\ Dr. Schanz, Alms \& Company AG, Dufourstrasse 24, Zurich 8008, Switzerland. \\ E-mail: kai-uwe.schanz@schanz-alms.com
}

\begin{abstract}
Against the backdrop of the credit crisis, the paper looks into the crucial role of trust and reputation in the insurance industry. We also offer some specific recommendations for management to consider in order to preserve these indispensable intangible assets in times of evaporating confidence, freezing credit markets and contracting economies. Admittedly, compared with banks, insurers are less vulnerable to a life-threatening, sudden withdrawal of trust as policyholders pay premiums upfront and, generally, exercise no direct influence on the level of claims. However, from a longer-term perspective, maintaining trust in the industry in general and in their respective company in particular can be viewed as the most fundamental objective an insurer's management has to meet.
\end{abstract}

The Geneva Papers (2009) 34, 260-270. doi:10.1057/gpp.2009.4

Keywords: credit crisis; trust; insurance business model; corporate communications

\section{Introduction}

The subprime crisis which hit the United States in summer 2007 and morphed into a full-blown global financial upheaval in autumn 2008 has taken a heavy toll on the insurance industry. Some industry players with significant financial market and banking operations were seriously damaged by the dramatic deterioration of global credit conditions and suffered severe losses requiring public support or even bail-out measures. But these were spectacular exceptions, rather than the rule. The vast majority of insurers and reinsurers felt the impact of the credit crisis through realised and unrealised investment losses as well as increasing insurance claims from the directors and officers' liability and errors and omissions lines of business. As insurers are significant institutional asset managers and underwriters of liability risks, these losses did not come as a surprise and were, in their large majority, well within the scope of corporate risk scenarios and models. The solvency position of most insurers weathered the financial tsunami and the industry as a whole did not pose any systemic threat to the global financial system - in stark contrast to the banking sector. ${ }^{1}$

This comparatively mild assessment notwithstanding, the insurance industry's reputation and image have been dealt a blow, with stakeholders' eyes on the fate suffered by former industry icons such as AIG and Fortis, companies that were felled

\footnotetext{
${ }^{1}$ See Swiss Re (2008) and Liedtke and Schanz (2008) for a general overview.
} 
by their non-insurance operations. Policyholders', investors' and employees' trust in the sector has been dented - and the fact that other financial services players have suffered on an even larger scale is a cold consolation, at best. These losses in reputation and trust represent an extraordinary threat to an industry that basically sells contingent promises to pay and is, therefore, based on credits of trust and reputation awarded by relevant stakeholders.

Against the backdrop of the credit crisis, the following paper looks into the crucial role of trust and reputation in the insurance industry. We also offer some specific recommendations for management to consider in order to preserve these indispensable intangible assets in times of evaporating confidence, freezing credit markets and contracting economies. Admittedly, compared with banks, insurers are less vulnerable to a life-threatening, sudden withdrawal of trust as policyholders pay premiums upfront and, generally, exercise no direct influence on the level of claims. However, from a longer-term perspective, maintaining trust in the industry in general and their respective company in particular can be viewed as the most fundamental objective an insurer's management has to meet.

\section{The role of trust and reputation in insurance}

For the purpose of this paper, trust in an organisation is defined as "a bet on its future contingent actions", 2 with four major factors supporting it: (1) reputation, i.e. "a comprehensive set of enduring stakeholder perceptions, opinions and expectations", 3 (2) performance, (3) accountability and (4) appearance.

Let us take a closer look at these four factors: The concept of reputation is, obviously, very closely linked to that of trustworthiness even though there are crucial differences: whereas reputation can be regarded as a collective, public phenomenon, trust is a distinctly individual and subjective view of an organisation's trustworthiness. ${ }^{4}$

Performance is another key determinant of trust. Trust will not endure if corporate performance fails to meet stakeholder expectations. This simple insight suggests that the task of building and maintaining stakeholder trust falls primarily and directly with chief executives, rather than support functions such as Corporate Communications, Investor Relations and Human Resources.

Accountability plays a critical role whenever stakeholders interact directly with an organisation. The appointment and availability of a counterpart who is appropriately empowered to deal with a stakeholder's request or address a specific need is of particular importance to large and complex organisations which can easily jeopardise trust capital based on a perceived lack of accountability.

Appearance is the softest element contributing to trust. It is of particular importance to the insurance industry as it sells intangible and abstract services. An appearance which conveys a tangible and sympathetic image, for example through human faces on an organisation's website, can make a significant contribution to building trust.

\footnotetext{
2 Sztompka (1999).

${ }^{3}$ Schanz (2006).

${ }^{4}$ Liedtke and Schanz (2006).
} 
It is undisputed that trust is an indispensable ingredient of insurance business. Insurers are actually in the "business of trust". They sell contingent promises to pay, more often than not at a distant point in the future. From a policyholder's perspective the insurer's willingness and ability to fulfil these promises cannot be assessed until a claim has been filed and settled. The insurer's performance is only incompletely observable at the time of signing an insurance policy. Information asymmetries make it difficult for the policyholder to instantly judge and assess the value of an insurer's promise to pay. Where this occurs, the reputation, performance, accountability and appearance of an insurance company are instrumental in generating trust with policyholders. This is particularly true for lines of business where settlement periods may run into decades, such as annuity policies. It follows that, for the insurance industry, the trust of policyholders and other stakeholders is a necessary pre-condition for conducting business. ${ }^{5}$

\section{Maintaining trust in times of turmoil}

How can a solid and well-performing insurance company maintain stakeholder trust in times of market dislocation? How can it prevent or minimise collateral damage from a general deterioration of sentiment? How can the company detach itself from a general crisis of confidence affecting the financial services industry? We suggest a simple answer: "Consistently deliver the promise and redouble your communication efforts".

From an economic perspective, trust is rooted in repeated interaction, which leads stakeholders to expect a company to perform and communicate in a certain way. Performance and communication can therefore be regarded as key ingredients of any systematic approach to building trust and reputation as well as to safeguarding these assets in times of crisis. Most insurance companies have weathered the storm of the subprime and subsequent financial crisis relatively well. Earnings have declined sharply but capital positions remained largely intact. Nonetheless, the woes of some former icons of the global insurance industry and the dramatic proportions of the banking crisis have led to widespread uncertainty among insurance stakeholders. Investors attach higher default probabilities to insurance securities, policyholders fret about their insurers' claims payment ability and employees are concerned about their jobs and demoralised by public bashing of global finance. There is no doubt that the reputation of the insurance industry as a whole has suffered as a consequence of the financial crisis and the dismal performance of the banking sector. In such an environment, companies who succeed in maintaining relevant stakeholders' trust and minimising spill-over effects from general public sentiment stand to benefit hugely as investors, customers and employees are likely to defect from their less favourably perceived competitors.

In the following sections we endeavour to put our recommendation "Consistently deliver the promise and redouble your communication efforts" into operation.

\footnotetext{
${ }^{5}$ See Lev (2005a) for a comprehensive economic discussion of reputation and trust.
} 


\section{The role of corporate performance}

\section{Core business processes}

The necessary condition for preserving stakeholder trust in trying times is to maintain corporate performance at expected levels. ${ }^{6}$ As far as policyholder trust is concerned, a regular and critical review of its core business processes is the most promising approach for any insurance company: Do we continue to display product excellence and innovative leadership or do we appear to be paralysed by the crisis? Do we maintain our selling standards or do we allow marketing standards to slip? Do we stick to our underwriting standards or do we start compromising in order to defend market share? Do we continue to settle claims expeditiously or do we succumb to the temptation to slow processes and introduce bureaucratic hurdles?

In other words: do all these elements of the value chain continue to perform in a way which would prompt stakeholders to make favourable "bets on a company's future contingent actions"?? Of course, maintaining performance standards in times of crisis and corporate belt-tightening is a demanding proposition as available budgets are likely to be reduced. However, each company should carefully evaluate the potentially crippling effects on policyholder trust from making indiscriminate cuts in critical parts of the value chain, that is those which stakeholders experience in their interaction with the company.

From an investor relations perspective the same reasoning applies: what are the costs and benefits of responding to a crisis by, let us say, cutting dividend payments, suspending share buy-back programmes or withdrawing previous performance guidance?

\section{Core corporate processes}

Besides core business processes, there is another crucial dimension of building and maintaining trust: core corporate processes such as corporate governance, disclosure and ethics. Which checks and balances are in place between an organisation's Board of Directors and executive team? How are operational, market and credit risks analysed, internally and externally reported, controlled and acted upon? How are compensation schemes set and aligned with stakeholders' long-term interests in the company? Which ethical standards govern the management of the company? These questions need to be answered convincingly, openly and regularly to maintain trust capital in turbulent waters.

\section{The role of corporate communication}

In times of crisis, stakeholders' thirst for instantaneous, comprehensive, transparent and understandable information increases exponentially. Corporate communication efforts therefore assume a critical role as severe industry crises may prompt customers to lose trust even in those companies who managed to escape relatively unscathed

\footnotetext{
${ }^{6}$ Lev (2005a), p. 12

${ }^{7}$ Sztompka (1999).
} 
from the general turmoil. In situations of panic and despair even the biggest reservoirs of trust capital seem to be in jeopardy. Maintaining performance of core business and corporate processes, as described in the section above, is therefore just a necessary condition for maintaining trust in times of turmoil. The sufficient condition is an approach to communication which takes into account stakeholders' specific needs for information and the risks arising from irrational collective behaviour driven by ubiquitous panic and gloom. The spectrum of measures to be designed and implemented ranges from outreach to relevant media, state-of-the art web tools, specific trainings and materials for customer-facing employees.

In the following sections we outline some key success factors of corporate communication management aiming at preserving a well-run insurance company's trustworthiness and reputation in times of a severe industry crisis.

\section{Speed}

The credit crisis has demonstrated that even the most venerable and reputable institutions can find themselves on the brink of demise within a few days or even hours. In jittery and panicky markets, a 24/7 communication mode is of vital importance. For this to work, internal decision-making processes need to be defined which ensure an instantaneous response to short-notice challenges, for example rumours on a company's impending insolvency, which spread at the speed of light. Direct access of the company's communication professionals to the CEO and Chairman, is indispensable and is a key imperative of communication risk management.

As speed must not come at the expense of quality and prudence, companies are welladvised to prepare for a maximum number of relevant communication contingencies before they arise, for example having statements on critical issues such as mergers and acquisitions, solvency, liquidity, changes to senior management, regulatory action and rating agency decisions.

Whether these requirements are met or not can decide the fate of a bank when it is faced with a run. Insurers are usually in a more comfortable position as contracts are more difficult to cancel for policyholders. Nonetheless, speed matters, especially in life insurance, where cancellation rights exist. As regards shareholders, however, insurers face the same challenge as other industries in crisis-stricken market conditions: quell concerns as they arise or face massive sell-outs.

\section{Transparency and simplicity}

Another key lesson from the credit crisis is the need for massive improvements in meaningful and understandable transparency. The complexity and opacity of certain financial products had grown to such proportions that even senior finance executive failed to keep pace with these developments - let alone ordinary investors or the public at large. Against this backdrop, transparency and simplicity are back in vogue - both in terms of product features and communication. "Keeping things straight and simple" will be a key success factor as investors, policyholders, employees and other stakeholders have lost faith in complex and esoteric structures and wordings. For insurers, this challenge is a long-standing one. They have been consistently criticised 
by various stakeholders for their inability to communicate transparently and understandably. Arguably, these weaknesses have impaired sales and driven up the cost of capital. In times of crisis, communication deficits of this kind could turn out to be even costlier. Avoiding these costs could be a powerful incentive to fundamentally review the current paradigm of communication in the insurance industry. In addition, a continuing lack of transparency and simplicity threatens to prolong the current, unprecedented public suspicion vis-à-vis innovative financial products. In the long run, this may prove to be the biggest cost factor for companies and their stakeholders alike.

\section{Consistency}

It is a "golden rule" of corporate communication to convey a consistent set of messages to all stakeholders. Differences should be restricted to the message's angle, sophistication and level of detail but never extend to its very core. In times of smooth sailing consistent communication helps companies maximise their credibility and reputation with stakeholders. In times of crisis, the stakes are much higher: inconsistent messaging is set to fuel uncertainty among stakeholders and may induce erratic and seemingly irrational behaviour - to the detriment of the company.

Apart from content, consistency is about timing. Ideally, all main stakeholder groups should be provided simultaneously with relevant, properly tailored information. From a legal perspective, violating this principle in respect of share price-sensitive information may result in unfair disclosure charges, sanctions from stock market supervisors and a loss in reputation vis-à-vis capital markets.

From an internal communication perspective, a maximum of consistency in message delivery is crucial to maintaining trust and staff morale, especially in times of crisis. It has a devastating effect on employees' commitment and motivation to learn major news about their company from the papers.

Obviously, meeting the imperative of consistency places a significant strain on a company's corporate communication function. Coordinating messages and the timing of their delivery is demanding, but they are key prerequisites to successful crisis communication.

\section{Holistic messaging}

A balanced messaging approach that incorporates internal and external as well as financial and non-financial aspects is likely to generate the maximum benefits in terms of quality and effectiveness of stakeholder communication. For this purpose, an integrated corporate messaging process is suggested. ${ }^{8}$

It is crucial to strike an appropriate balance between (1) financial and operating performance (the traditional focus of corporate disclosure), (2) the company's vision, mission and strategic direction and (3) its competitive position in the industry and

\footnotetext{
${ }^{8}$ The following section draws on Eccles et al. (2001).
} 
overall socio-economic context. Demonstrating that an insurer is more than just a profit-generating abstract entity is especially relevant in times of crisis when reservoirs of trust are most jeopardised. Insurers are well-advised to constantly emphasise their vital contribution to economic and societal progress - from peak risk mitigation enabling entrepreneurial risk-taking and innovation to comprehensive financial protection offering "peace of mind" for millions of policyholders.

\section{Third-party support and endorsement}

In times of crisis and uncertainty, the credibility of individual companies tends to erode - more often than not regardless of objectively measurable differences in performance. All the more important is the effective use of credible third-party bodies to substantiate views expressed on behalf of the industry or individual companies. Among such institutions are think tanks known for expressing independent, researchbacked views. In global insurance, The Geneva Association is widely regarded as the leading institution of its kind. Building close relationships with these bodies pre-crisis is a wise proposition for insurance companies. Such institutions tend to be of particular value to the industry in times of a wholesale evaporation of trust and confidence. In such circumstances, the industry relies heavily on supporting voices with a reputation for impartiality and academic rigour. The think tanks, especially in times of crisis, face the challenge of maintaining a unique profile that clearly differentiates them from trade associations and other lobbying bodies. In addition, as crises strike and emotions run high, think tanks have to weigh carefully between their rigorous academic standards on the one hand and the (necessary) courage to enter reasonably simplified arguments into the public debate on the other.

\section{A well-balanced channels mix}

Optimising the mix of channels deployed is a key challenge for corporate communications management - even in times of smooth sailing. In turbulent waters, this challenge mounts tremendously as the stakes are significantly higher.

\section{The media}

We argue that, especially in times of turmoil, retail insurers with millions of individual policyholders should focus their communication efforts on the print and electronic media. ${ }^{9}$ As confidence in the corporate sector unravels, target audiences attach a particular importance to what they perceive as quasi-objective media reporting. Insurers who excel in crisis media relations stand to benefit on client, capital and talent markets (see the next section).

But just advising redoubling of media relations efforts would be insufficient and inappropriate. In times of financial and economic crisis, insurance companies have to tread very carefully with journalists as these tend to be particularly critical and are

\footnotetext{
${ }^{9}$ See Eccles and Vollbracht (2006) for the benefits of a proactive stance on media relations, especially in turbulent times.
} 
likely to put any pro-actively shared information under microscopic scrutiny. This potential downside needs to be managed diligently by media relations professionals.

\section{Stakeholder meetings}

As uncertainty spreads and confidence wanes, face-to-face communication gains in importance. This seems to be a truism based on common sense. Still, many companies fail to live up to this imperative when it would be most important to do so. The reasons are obvious: senior executives are fully tied up with the specific operational challenges arising from a turbulent market environment. There is, however, no alternative for executive management to regularly meet with key constituencies such as opinion-shaping customers, major investors and employees across hierarchical boundaries. An effective stabilisation of the stakeholder base is a prerequisite to successfully navigating the corporate ship through troubled waters. This simple piece of advice, unfortunately, is often ignored as companies switch to crisis mode and top management becomes fully absorbed by operational tasks.

\section{The web}

The corporate website should be made the key repository for crisis-related information, be it industry-related or company-specific. A special section should be established featuring regularly updated Frequently Asked Questions, corporate public statements as well as credible third-party materials. In addition, the interactive features of the website should be expanded during times of crisis as direct stakeholder communication assumes a decisive role.

\section{Electronic newsletters}

The pull-elements of the corporate website should be complemented by regular electronic newsletters. These, obviously, are a standard push-tool in calm waters, too. But as soon as the going gets rough, "time to market" becomes critical. Uncertainty, mounting concerns and outright panic may prompt stakeholders to take premature and irrational decisions based on the latest piece of information available. Any company determined to counter that risk will have to shift to the top gear of communication by issuing relevant information at the highest possible frequency. For that purpose, electronic stakeholder newsletters to investors, customers and employees are an important complement to media releases. It is needless to add that implementing this recommendation would stretch any corporate communications department to the limit, not least because of mandatory coordination requirements for listed companies who have to comply with fair-disclosure regulations.

\section{Print publications}

The traditional tool of print publications should not be ignored during times of crisis. It may add significant value, especially to those companies who boast of particular expertise and knowledge. Authoritative and detailed publications on risk-related topics that are relevant to the economy and society at large may not reach large audiences. They are, however, very effective in maintaining the goodwill of 
stakeholder groups that largely matter such as decision-makers in client companies, institutional investors and regulatory authorities.

\section{Rewards from pro-active stakeholder management in times of turmoil ${ }^{10}$}

Conventional wisdom has it that stakeholder trust will yield commercial benefits; while its evaporation can quickly drag a firm to the brink of demise, and ultimately tip it over the edge, especially in banking when institutions face a run.

\section{Client markets}

The trust of existing customers and a solid reputation with prospective clients is set to result in more successful business production, be it direct sales or business generated through intermediaries. This is particularly true for an intangible business like insurance whose benefits can only be assessed after concluding the respective insurance contract and making premium payments. Further, trust and reputation could even enable an insurance company to command a premium on market prices. In other words, both determinants of a company's revenues, that is quantity and price, could be favourably affected by trust and reputation.

In phases of turmoil, superior trust and reputation established in more stable times will pay off: the prospects of retaining business will increase. It is even likely that a trusted company will expand its market share at the expense of less favourably perceived rivals. Durable trust and reputation may be instrumental in reshaping the marketplace and establishing a much stronger corporate position post-crisis.

\section{Capital markets}

On the capital markets, the first-class reputation of a company is likely to be rewarded in the form of an improved creditworthiness, and, in stable market phases, with a market valuation in excess of the book value. When the going gets rough, companies with a superior reputation should benefit through less severe drops in their share price, costs of capital rising at a slower pace than for its rivals and financial flexibility maintained at above-average levels.

\section{Talent markets}

An above-average corporate and industry reputation will have a positive effect on recruitment. Attracting top-level managers and specialist employees has always been challenging for the insurance industry, lacking the appeal and glamour of other financial market players in the search for talent. One may argue, though, that the credit crisis, the subsequent demise of Wall Street's investment banking business model and the severe reputational damage suffered by the banking industry as a whole have

\footnotetext{
${ }^{10}$ This section draws on Lev (2005a, b) and Schanz (2005).
} 
removed this structural disadvantage. In addition, given the unprecedented calamities that have hit global finance, employees' options for defecting have sharply reduced.

Nonetheless, even in times of crisis, employees' trust in their company and the general reputation it enjoys in the marketplace can prove a key competitive advantage. With morale sagging across companies and industries, successful employee relations based on trust and supported by corporate reputation can make the difference when it comes to maintaining productivity and performance in stormy waters.

\section{Conclusions}

The subprime and subsequent financial crises have served as powerful reminders of the crucial role of trust as a lubricant of finance and commerce. As we have witnessed, the evaporation of confidence between market participants can stall the most fundamental mechanisms of interbank lending with devastating consequences for global credit markets and, ultimately, the real economy.

Even though their distinct business model makes insurers less vulnerable to an unexpected loss of confidence than banks, (policyholder) trust remains a pre-requisite to doing insurance business - be it the annual extension of motor policies or the conclusion of long-term life insurance policies.

In times of crisis, insurers need to maintain an appropriate balance between performance and communication management in order to preserve stakeholder trust and capitalise on the woes of more severely hit rivals. Despite organisational stress, rising claims (including fraudulent claims) and a multitude of other crisis-induced challenges, insurers must maintain their operating standards in underwriting, policy administration, claims management and other vital areas of the value chain. Trust is generated through direct interaction between a company and its stakeholders. Any slippage in operating standards could easily erode or even deplete trust capital.

Apart from a continued focus on key business and corporate processes an insurer aiming at minimising the impact of crisis, needs to step up corporate communication activities to meet stakeholders' increasing needs for timely, relevant and transparent information disseminated through a carefully balanced mix of channels.

An insurance company, which consciously manages its trust capital as suggested in this paper stands a good chance of weathering the worst fall-out from the crisis, emerge stronger from it and reap significant commercial benefits as soon as the crisis has receded.

\section{References}

Eccles, R.G., Herz, R.H., Keegan, M.E. and Phillips, D.M. (2001) The Value Reporting Revolution, Hoboken, NJ: John Wiley \& Sons.

Eccles, R.G. and Vollbracht, M. (2006) 'Media reputation of the insurance industry: An urgent call for strategic communication management', The Geneva Papers on Risk and Insurance 31(3): 395-408.

Lev, B. (2005a) The Art and Science of Valuing Intangibles and Managing Reputation, presentation at the 6th International Sustainability Leadership Symposium, available at www. http://www.sustainabilityzurich.org.

Lev, B. (2005b) 'Intangible assets: Concepts and measurements', Encyclopedia of Social Measurement 2: 299-305. 
Liedtke, P.M. and Schanz, K. (2006) 'Success factor reputation management: Some thoughts from the insurance industry', The Geneva Association: Insurance and Finance Newsletter 2: 5-6.

Liedtke, P.M. and Schanz, K. (2008) 'Navigating the storm', Global Reinsurance, December 2008/January 2009: 11-13.

Schanz, K. (2005) Stakeholder Management in Insurance: A Critical Determinant of Corporate Performance, Seminar Proceedings, 2005 Annual Seminar of the International Insurance Society, Hong Kong.

Schanz, K. (2006) 'Reputation and reputational risk management', The Geneva Papers on Risk and Insurance - Issues and Practice 31(3): 377-381.

Swiss Re (2008) Global Insurance Review 2008 and Outlook 2009: Weathering the Storm, Economic Research \& Consulting, Special Report, 9 December 2008, available at www.swissre.com.

Sztompka, P. (1999) Trust - A Sociological Theory, Cambridge U.K.: Cambridge University Press: 14-15.

\section{About the Author}

Kai-Uwe Schanz is Principal Partner of Dr. Schanz, Alms \& Company and Chairman of the Geneva Association's Chief Communication Officers Network. He studied Economics in Germany and Switzerland and obtained a Phd from the University of St. Gallen. From 2004 to 2007 he served as Chief Communication and Corporate Development Officer at Converium. From 1995 to 2004 he worked for Swiss Re, performing various senior management roles such as Chief Economist Asia-Pacific. In 2003, he was appointed Research Fellow at the China Centre for Insurance and Social Security Research at Beijing University. In 2005 he received the Geneva Association/ International Insurance Society Research Award. Dr. Schanz is also a member of the Board of Governors of the Asia-Pacific Risk and Insurance Association, Singapore. 